\title{
Una visión histórica de la rabia en Chile
}

\author{
Enrique Laval R. y Paulina Lepe I.
}

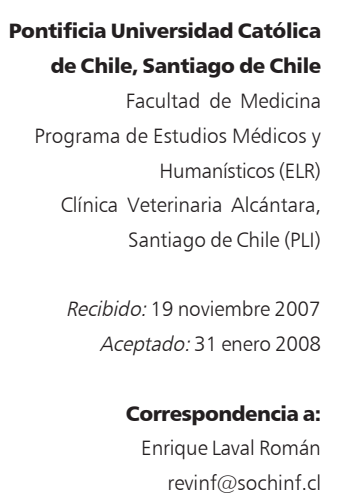

\section{An historical view of rabies in Chile}

In this review international and national historical features of rabies are presented remarking the start of preventive immunization in Chile, at year 1896, with the creation of the first service for rabies vaccination and la descentralización of preventive treatment from year 1929. Figures of human cases produced by this zoonosis between 1950 and 1986 are described, señalándose changes that occurred in local epidemiology of rabies since 1990, with an endemic pattern in bats and almost disappearance of canine rabies.

Key words: rabies, history, vaccination, Chile.

Palabras clave: rabia, historia, vacunación, Chile.

\section{Antecedentes históricos}

$\mathrm{L}$ a rabia es una zoonosis producida por un virus ARN, género Lysavirus, de la familia Rabdoviridae, que infecta a numerosos animales, especialmente mamíferos. Posee dos antígenos principales, uno externo, gluco-proteico, responsable de los anticuerpos neutralizantes y otro interno, núcleo-proteico, grupo específico, que genera anticuerpos útiles en el diagnóstico de la rabia intracerebral, sin eficacia protectora. Desde el punto de vista anátomo-clínico, es una encéfalo-mielitis aguda viral. Su vía de transmisión puede ser directa (mordeduras, lameduras, rasguños producidos por el animal enfermo) o indirecta (inhalación de secreciones e incluso trasplantes de órganos de individuos enfermos ${ }^{1}$.

Las primeras civilizaciones del Medio Oriente ya la conocían, incluyendo a los egipcios, que la mencionan en el Código de Eshunna, en el año 2300 aC, aunque otros historiadores dicen que fue descrita primero en la Mesopotamia, allá por el 1800 aC². Aristóteles la cita en animales y habla de su posible transmisión desde el perro, pero cree refractario al hombre. Es interesante mencionar que el importante médico del Renacimiento, Jerónimo Fracastoro (1478-1553) comparte, inicialmente, lo afirmado por Aristóteles: "los animales a causa del estado salvaje, en el cual tienen la semejanza con el perro, una vez que han sufrido el contagio, se vuelven rabiosos. Pero la naturaleza del hombre es muy lejana de aquel estado salvaje y de aquella semejanza, no poseyendo un elemento análogo que reciba en seguida el contagio. Se vuelven rabiosos todos los animales que han sido mordidos, a excepción del hombre". Con posterioridad "piensa que Aristóteles quiso decir en vez de a excepción del hombre, antes del hombre"3.

Epicarmos y Demócrito llamaron a la enfermedad "lyssa", palabra griega que significa gusano. Hasta casi mediados del siglo XVIII, se creía que la rabia era producida por unos gusanillos que desde debajo de la lengua invadían el cerebro ${ }^{4}$.

Aureliano fue el primero en señalar la hidrofobia como síntoma y signo importante de la enfermedad. Celso, quien conoció bien la rabia, escribía en el año 30 de nuestra era: "si alguien mordido no es rápida y enérgicamente tratado, enferma de hidrofobia, padeciendo dolorosa y lamentablemente sin esperanza de salvación. El veneno debe ser extraído de la sangre mediante ventosas y cauterizando con fuego el sitio lesionado". Galeno aconsejaba la sección inmediata de los tejidos mordidos ${ }^{4,5}$.

Según el doctor Sanz, médico guatemalteco e historiador de la Medicina, "antiguamente se arrojaba al mar a los rabiosos hasta provocarles síntomas de asfixia por sumersión", agregando que el poeta Eurípides habría sido curado por este método. Afirma que en Quesaltenango, "entierran hasta el cuello a los rabiosos"; lo mismo que en Amsterdam donde contaba con muchos partidarios ${ }^{6}$.

Hasta fines de la Antigüedad y durante la Edad Media, los autores aportaron nuevas observaciones, pero se perdieron en una terapéutica extremadamente variada: fue la época de las pociones cabalísticas, de las peregrinaciones a San Huberto de Ardennes y de 


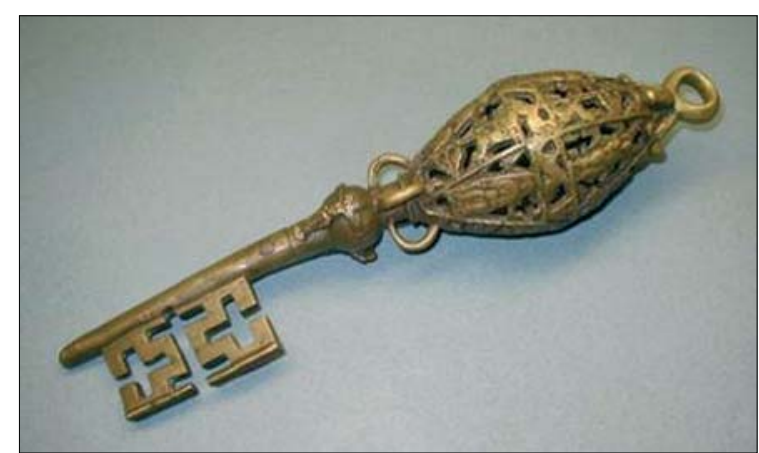

Figura 1. Llave de San Huberto de Ardennes. Amuleto contra la rabia, utilizado hasta fines de la Antigüedad y durante la Edad Media.

procedimientos tales como comprimir a los enfermos de rabia entre dos colchones para evitar la contaminación del aire ${ }^{5}$

En 1198, Maimónides escribió en su tratado sobre Venenos y Antídotos que "todo en la literatura contra la mordedura de un perro loco es útil, sólo cuando se aplica antes de que se desarrolle la rabia. Cuando éste es el caso, aún no he visto a nadie que haya escapado con vida".

La rabia no parece haber sido conocida en el Nuevo Mundo antes de la llegada de los europeos y quizás fue introducida en América del Norte y del Sur por los perros que acompañaban a los conquistadores ${ }^{2}$. Según Unanue, la enfermedad apareció por primera vez en América Meridional en 1803 y en Perú (Arequipa) en $1807^{7}$.

En el siglo XIX se demuestra la virulencia de la saliva en el perro y en los carnívoros (Grüner, Berndt, Magendie, Hertwig), en los herbívoros (Berndt, Brechet, Rey) y en el hombre (Magendie y Brechet). Las investigaciones más importantes son las que se refieren a la localización nerviosa del virus rábico (Brown-Séquard, Duboué, Boerhave, Jaccoud) y la contagiosidad de la enfermedad.

Zinke en 1804 inoculó, por primera vez, la rabia de un perro enfermo a otro sano, pincelándole una herida con la baba del primero. El médico veterinario leonés Galtier demostró, entre 1879 y 1881, la receptividad del conejo y precisó los distintos grados de virulencia de los productos infecciosos, efectuando los primeros ensayos de vacunación anti-rábica al intentar inmunizar carneros y cabras con inyecciones intravenosas del virus, pero no pudo provocar con certeza la rabia inoculando bajo la piel sustancia nerviosa que contenía el virus ${ }^{4,5}$.

En 1882, más afortunado que Galtier fue Pasteur, quien llegó a los resultados del veterinario leonés por inyección intracerebral. Obtuvo en el conejo un virus reforzado de incubación fija: el llamado "virus fijo". En 1885 probó la posibilidad de vacunar perros por medio de virus atenuados; después de los éxitos conseguidos en animales y siguiendo los consejos tanto de Vulpian como de Grancher, se decidió a experimentar su método en el hombre. En julio de aquel año utilizó por primera vez inyecciones múltiples de una suspensión preparada a partir de médula espinal de conejo, infectada y desecada, que contenía una cantidad variable de virus de la rabia, en un niño de ocho años, Joseph Meister, gravemente mordido por un perro rabioso, quien recibió 13 inoculaciones practicadas por el doctor Grancher. En el mes de octubre repitió la operación en un joven pastor de Jura, Juan Bautista Jupille, aún más cruelmente mordido que Meister, los que no enfermaron de rabia. Este trascendental acontecimiento marcó la iniciación de la vacunación antirábica ${ }^{4,5,8}$.

En adelante, muchas veces los médicos se encontrarían en presencia de un caso de mordedura y se les preguntaría si el animal mordedor está atacado de rabia, si debe ser muerto, qué debe hacerse con el cadáver. Por último, qué personas están expuestas a contraer la enfermedad y deben someterse al tratamiento preventivo porque, a partir de la acción de Pasteur, la rabia será una enfermedad mucho más fácil de prevenir que de tratar, encaminándose los trabajos del siglo XX

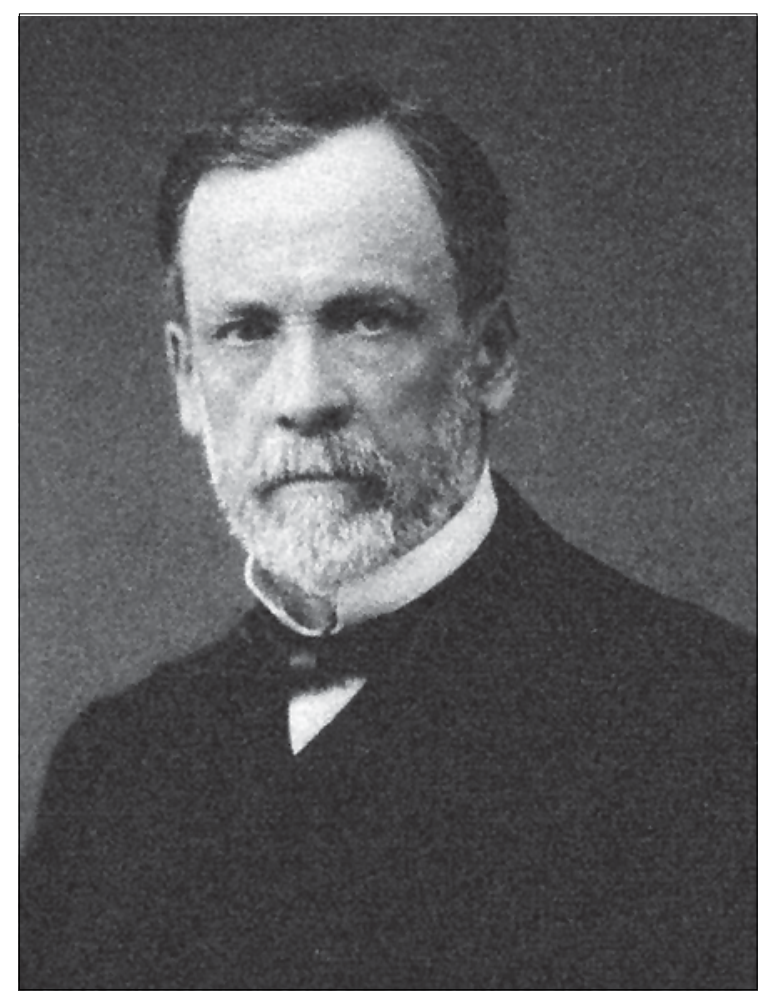

Figura 2. Luis Pasteur. Aplicó con éxito por primera vez la vacunación anti-rábica en humanos. 
al mejor conocimiento de la inmunología de aquélla, para perfeccionar la vacunación anti-rábica ${ }^{5,8}$.

Habría que agregar el descubrimiento en 1903, por el histólogo italiano Negri, de los corpúsculos intracitoplasmáticos específicos, conglomerados virales, que se encuentran especialmente en las neuronas del asta de Ammón, en los individuos y animales fallecidos de rabia $^{1,2}$.

Si bien en 1835, Charles Darwin publicó en observaciones y notas sobre sus viajes, la existencia de "hidrofobia en los valles de Chile", diríamos que en el país, todo comenzó con la primera comunicación clínica sobre rabia, por el cirujano de la Armada don Pedro Videla Ordenes, en abril de 1879. En el escrito, que fue su tesis para optar al título de Licenciado en Medicina, se explaya sobre la rabia en general, refiriéndose a tres enfermos atendidos por él; a teorías acerca de la naturaleza de la enfermedad; analogías y diferencias sobre la rabia humana y la animal, negando la "producción espontánea" de esta entidad. Además, plantea algunas consideraciones sobre el empleo del Datura stramonium (chamico) en su tratamiento, concluyendo "que si bien no puede curar, por lo menos alivia los síntomas molestos de la enfermedad, ya que calma y disminuye la acción excitante de los centros nerviosos producida por el virus"6,7.

\section{Iniciación de la vacunación anti-rábica en Chile}

En el año 1896, el profesor Mamerto Cadiz, implantó en Chile, el Servicio de Vacunación Anti-rábica y desde esa fecha hasta el año 1929 inclusive, recibieron los beneficios de la vacunación preventiva 7.060 personas ${ }^{9}$.

Fue el doctor Teodoro Muhm quien trajo desde Buenos Aires el virus fijo del Instituto Pasteur, comentando que "con motivo de la reciente instalación del Servicio de Vacunación Anti-rábica en nuestro país y de haberme correspondido el honor de intervenir directamente en ella, creo oportuno dejar constancia de su utilidad y de los primeros casos que han sido sometidos a este tratamiento". A partir de 1886, empezaron a fundarse en distintos países, laboratorios antirábicos, entre otros, el Laboratorio Pasteur de Buenos Aires.

Según el doctor Muhm "en nuestro país no se manifestó de necesidad urgente la creación de un servicio análogo, por cuanto la creencia general ha sido de que la rabia era una afección sumamente rara en Chile, incluso enteramente desconocida", lo que fue un gran error negar su existencia. En Buenos Aires, estudió la preparación de la vacuna anti-rábica y trajo al país el virus necesario para elaborarla, con un conejo rábico del pasaje 580, correspondiente a la serie de Pasteur. En seguida, dio cuenta de las primeras cinco personas sometidas a vacunación anti-rábica, a comienzos del año 1896. Dos habían sido mordidas en Santiago, una en Peñaflor (Departamento de Victoria), una en San Javier de Loncomilla y una en La Calera. Por desgracia el tratamiento fue ineficaz en un joven en el que se inició a los 13 días de las mordeduras "y la vacuna no logró contrarrestar los efectos perniciosos que el virus rábico ya había ejercido en el organismo de ese desgraciado". Los otros cuatro no tuvieron problemas, continuando en perfectas condiciones de salud.

Finalmente, el doctor Muhm relata la investigación de la muerte por rabia de un perro que le fue enviado por don Vicente Dávila Larraín, procedente de su fundo Pudahuel, informe que sería el primero realizado en el Servicio Anti-rábico: "hechas en dos conejos las correspondientes inoculaciones por trepanación, en el bulbo raquídeo del animal sospechoso, quedó confirmada la rabia de este animal, pues morían manifiestamente rabiosos los conejos inoculados, el día 19 de septiembre". La inoculación se había realizado el día 3 de septiembre de $1896^{10}$.

En el comentario que efectuó el ilustre profesor doctor Alejandro del Río, en el seno del Directorio de la Sociedad Médica sobre lo publicado por el doctor Teodoro Muhm, destacó que el Consejo de Higiene ha repetido hasta el cansancio sobre la necesidad de recurrir a una profilaxis racional de la rabia; "quizás la Facultad de Medicina reciba mejor premio por sus esfuerzos y consiga la introducción de las medidas que debemos reclamar enérgicamente".

Los profesores Ventura Carvallo e Isaac Ugarte adhirieron con gran entusiasmo a las palabras del doctor del Río y el profesor Federico Puga Borne, también presente, agregó: "ya el Consejo de Higiene ha indicado esta medida a la autoridad local, señalando además el establecimiento de una patente sobre los perros, el morral de alambre, la destrucción de los perros vagos, etc ${ }^{\prime 11}$.

A propósito del doctor Puga Borne, transcribimos lo siguiente del capítulo de las "Carnes virulentas" de su tratado de Elementos de Higiene: "M. Decroix, convencido de que la carne procedente de animales enfermos o muertos de cualquiera de las enfermedades conocidas es perfectamente propia para la alimentación, ha comido impunemente de todas las carnes reputadas insalubres, crudas y cocidas, comprendiendo entre ellas la del perro rabioso. En rigor la carne de estos animales no es peligrosa, pues que solo la saliva encierra el virus, pero en la práctica será prudente rehusarla siempre ${ }^{\prime 12}$. 


\section{Descentralización del tratamiento preventivo anti-rábico}

Los fracasos de la vacunación anti-rábica en las personas que se presentaban tardíamente al tratamiento, por tener su residencia lejos de los centros de vacunación, llevaron a estudiar métodos que permitieran enviar la vacuna a largas distancias, sin pérdida de su eficacia.

Roux demostró en 1887, que la glicerina neutra a 30 grados Baumé, conserva intacta y fija la virulencia durante un tiempo, del virus rábico. Kraus en Argentina, empleando series de médulas sumergidas en glicerina, llevó a cabo el procedimiento para descentralizar el tratamiento preventivo anti-rábico.

Trabajos en Italia, Rusia y Estados Unidos de Norteamérica, resolvieron definitivamente este problema, mediante el virus fijo muerto por la acción de sustancias químicas, utilizándose el método de Fermi, en que la sustancia nerviosa se trituraba finamente en suero fisiológico fenicado, lo que permitió envasar en ampollas la vacuna.

La correspondencia postal entre el Jefe de la Sección Seroterapia del Instituto de Higiene, doctor Mamerto Cadiz y el director de dicho Instituto, doctor Ricardo Dávila Boza, así como con el Intendente de Tarapacá y el Ministerio del Interior, por el número de personas mordidas por "perros presuntivamente rabiosos" en Iquique y zonas aledañas, mostraba en los años 1915 y 1916, que el "tratamiento preventivo es tanto más eficaz y seguro cuanto más rápidamente se le inicia y pierde su eficacia cuando se efectúa en una época tardía", según lo comunica en carta enviada al Ministro del Interior el doctor Ricardo Dávila Boza, enfatizando "que los pacientes que vienen de localidades alejadas del Instituto de Higiene, corren el peligro de tener un tratamiento ineficaz, lo que suele suceder a las personas que carecen de recursos para hacer los gastos de viaje y que necesitan obtener pasajes gratuitos en trenes y vapores, a causa de las dificultades con que tropiezan las autoridades locales para concederlos".

En la práctica, los tratamientos preventivos se podían realizar, en plazos convenientes, sólo en localidades o ciudades cercanas a la capital. Así, en 1921, el doctor Ricardo Zilleruelo, ayudante de la Sección Microscopía y Bacteriología del Instituto de Higiene, procedió a efectuar el tratamiento preventivo en Viña del Mar a cinco personas, que necesitando de éste, no podían trasladarse a Santiago. Empleó el método de las médulas en glicerina y los resultados satisfactorios que obtuvo, los consideró en su tesis "Transportación de la vacuna anti-rábica".

Bajo la dirección del Profesor Kraus, correspondió

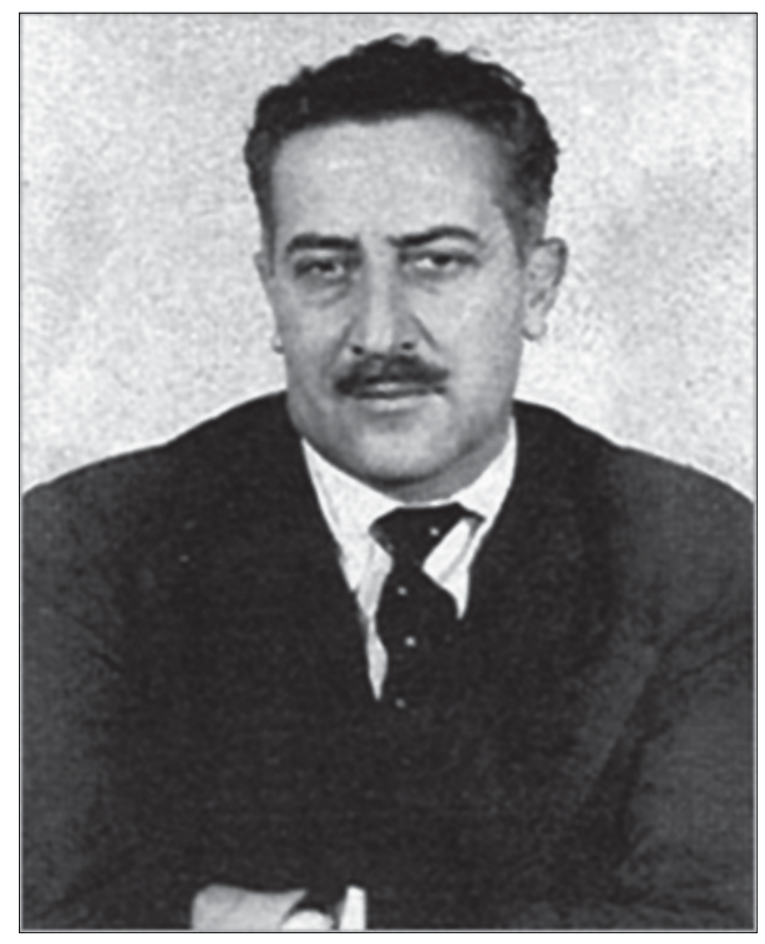

Figura 3. Dr. Eduardo Fuenzalida L., co creador de una vacuna anti-rábica en Chile, elaborada en cerebro de ratón lactante, en 1954. al Instituto Bacteriológico en 1929, resolver definitivamente la descentralización del servicio antirrábico en Chile $\mathrm{C}^{13,14}$.

\section{Rabia humana en Chile. Cambios epidemiológicos}

El Programa Nacional de Control de la Rabia, vigente en Chile desde los años sesenta, logró alcanzar su objetivo, la prevención de la rabia humana, mediante la vacunación de las personas expuestas y un fuerte componente de educación comunitaria. Además, consiguió interrumpir el ciclo de transmisión, controlando la rabia canina, principal fuente de infección para el hombre, con campañas masivas de vacunación antirábica y control selectivo de la población canina ${ }^{15}$.

Dentro de dicho programa, el uso tradicional de la vacuna Fuenzalida-Palacios, elaborada en cerebro de ratón lactante (CRL), hizo que esta zoonosis presentara una significativa disminución en nuestro país y en muchos otros que la han empleado sistemáticamente. Sin embargo, por contener tejido neural y potencialmente mielina, puede ocasionar accidentes neuro-paralíticos por un fenómeno inmunológico y alérgico. Utilizada en Chile hasta 2002, no ha habido constancia de la producción de dichos efectos adversos. En mar- 
zo del año 2003 se incorporó a los programas de prevención de rabia, vacunas elaboradas en líneas celulares, en reemplazo de vacunas tipo CRL y cuyo riesgo de accidente paralítico es sólo de 1/100.000 dosis administradas ${ }^{16,26}$.

Los datos epidemiológicos mostraban una evolución en forma endémica, con numerosos casos humanos y animales, en la década 1950 a 1959, en la que se confirmaron 52 en humanos, correspondiendo, la mayoría, a los años 1950 y 1955, con 11 enfermos en cada uno. Es necesario destacar la importancia que se dio en el país, a la campaña anti-rábica, con participación de la prensa y de la radio. Así el 1 de junio de 1955, el Presidente de la Sociedad Protectora de Animales, diputado don Jorge Meléndez Escobar, en cadena nacional de emisoras, habló sobre "el problema de la hidrofobia". Según El Mercurio de Santiago del 9 de junio, "en la segunda quincena del mes en curso será iniciada por el Servicio Nacional de Salud, la campaña de vacunación anti-rábica de perros en Santiago, programa que se proyectó realizar en tres a cuatro semanas, con la cooperación del Ejército, efectuándose vacunación domiciliaria en forma gratuita para proceder a la inmunización de los perros que existían en cada casa, esperándose vacunar más del $80 \%$ de la población canina. Por otra parte, las autoridades sanitarias procederán a recoger todos los perros que sean encontrados en la vía pública, tengan o no patente. Los que carezcan de ella serán sacrificados de inmediato y los otros podrán ser rescatados durante un plazo de 24 horas, al término del cual, también serán sacrificados".

Naturalmente, estas medidas llevaron a que distintas personalidades abordaran el problema desde los puntos de vista educacional, médico, salud pública y sentimientos humanos relacionados con el animal, respectivamente.

En parte de la declaración del Servicio Nacional de Salud, publicada en El Mercurio de Santiago del 14 de junio de 1955, se dice "que no es efectivo que en Estados Unidos, Inglaterra, Alemania, Francia e Italia, deambulen libremente los perros en la vía pública con el único requisito de la vacunación. Ni en éstos ni en otros países del orbe, se expone la comunidad a la mordedura de perros, como acontece aún, por desgracia en Santiago". Continúa la declaración "que los camiones-perrera no son una invención nacional, sino que circulan en todas las ciudades civili-

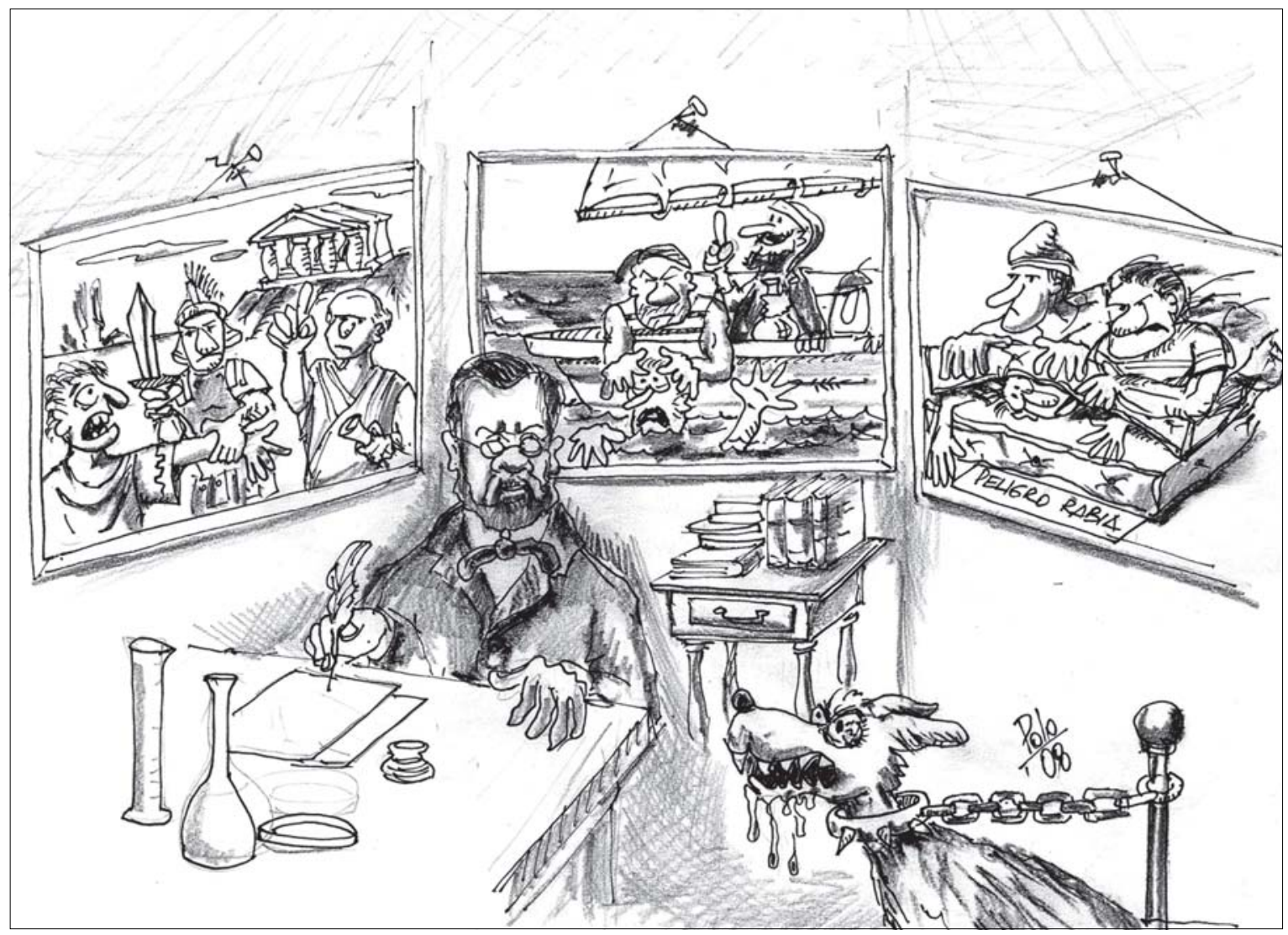


zadas, aun cuando el problema de los perros callejeros está en ellas muy lejos de la importancia que reviste en Chile. Tampoco es efectivo que se está haciendo uso de métodos crueles para el exterminio del perro vago. La inyección de cianuro saturado provoca una muerte instantánea y ha sido recomendada al Servicio por dirigentes de la Sociedad Protectora de Animales, que también la emplea"17-21.

En la década siguiente, 1960 a 1969, se diagnosticaron 24 casos humanos, confirmándose en Chillán, en 1972, el último enfermo por la variante canina del virus rábico. Las cepas de virus aisladas en perros con rabia (siete casos en los últimos 25 años) o gatos con rabia (dos casos en los últimos 17 años), corresponden a cepas propias de murciélagos insectívoros (Tadarida brasiliensis) existentes en nuestro territorio. En enero de 1985 fue detectado el primer brote de rabia en quirópteros, que afectó a 13 ejemplares, en las regiones Metropolitana, $\mathrm{V}$ y $\mathrm{VI}^{22,23,26}$.

En Rancagua, en el año 1986, ocurrió el caso de un niño de siete años, sin antecedentes de mordedura o exposición al virus, siendo la fuente de infección identificada, un murciélago encontrado entre los juguetes del niño, el cual cumplió el papel de reservorio del virus ${ }^{24,25}$.
La actual situación epidemiológica de la rabia en Chile se caracteriza por una endemia en murciélagos insectívoros, los cuales por sus hábitos antropofílicos habitan en centros urbanos, representando un riesgo para el hombre.

Se puede decir que desde 1990 se encuentra interrumpida la circulación de virus rábico de variedad canina y, en consecuencia, la rabia canina se ha eliminado en el país ${ }^{25,27}$.

\section{Resumen}

En esta comunicación se reseña antecedentes históricos de la rabia, a nivel mundial y nacional, destacándose la iniciación de la vacuna preventiva en Chile, en el año 1896, con la creación del primer servicio de vacunación anti-rábica y la descentralización del tratamiento preventivo, a partir de 1929. Se menciona el número de casos humanos con esta zoonosis entre 1950 y 1986, señalándose los cambios ocurridos en la epidemiología de la enfermedad en el país, desde 1990, con una endemia exclusiva en murciélagos y eventual desaparición de la rabia canina.

\section{Referencias}

1.- Repetto G. Enfermedades infecciosas inmunoprevenibles. Ed. Universidad Católica de Chile. Santiago de Chile. 2002.

2.- Mandell G, Gordon D R, Bennett J E. Enfermedades Infecciosas. Principios y Práctica. Ed. Panamericana. Bs. Aires. Rep. Argentina. 1991.

3.- Fracastoro J. De Contagio, de las enfermedades contagiosas y su curación. (traducido por Aníbal Ruiz Moreno) Talleres de Impta. Sección Educación para la Salud. SNS. Santiago de Chile. 1962.

4.- Pedro-Pons A. Enfermedades Infecciosas. Salvat Ed. Barcelona. España. 1952.

5.- Sergent E. Tratado de Patología Médica y Aplicada. Ed. Publ. Barcelona. España. 1933.

6.- Laval R E. La primera comunicación de rabia en Chile por el cirujano de la Armada don Pedro Videla Órdenes. Rev Chil Infect 2003; 20: 142-4.

7.- Favi M, Durán J C. Epidemiología de la rabia en Chile (1929-1988) y perspectivas en mamíferos silvestres. Avances en Ciencias Veterinarias 1991; 6: 13-21.

8.- Top F H. Communicable Diseases. Rabies. The C.V. Mosby Company Ed. St. Louis.
E.U.A. 1955.

9.- Durán A. La rabia en Chile. Rev Inst Bact Chile 1929; 1: 24-5.

10.- Muhm T. Comprobación experimental de la rabia en Chile. Instalación del Servicio de la vacuna antirrábica. Rev Méd Chile 1896; 24: 454-6

11.- Del Río A. Sobre la rabia y vacunación antirrábica en Chile. Rev Méd Chile 1896; 24: 472-4.

12.- Puga Borne F. Elementos de Higiene. Tomo II. Impta. Gutenberg. Santiago de Chile. 1891.

13.- Orellana E. Descentralización del tratamiento antirrábico. Rev Inst Bact Chile 1929; 1: 39-41.

14.- Dávila B R. La rabia en el país. Su profilaxis. Rev Chil Hig 1916; 22: 88-97.

15.- Eliminación de la rabia trasmitida por perros. Chile: situación epidemiológica. OPS 2003; 30-31. (sin nombre del autor)

16.- Fuenzalida E, Palacios R. Un método mejorado en la preparación de la vacuna antirrábica. Presentado en la $3^{\text {a }}$ Jornada de la Sociedad Chilena de Salubridad. Santiago de Chile. 1954.

17.- El problema de la Hidrofobia en Chile. El Mercurio de Santiago. 1 de junio de 1955.
18.- Plan para la vacunación de perros contra la Hidrofobia. El Mercurio de Santiago. 9 de junio de 1955.

19.- Campaña intensiva de vacunación antirrábica de perros. El Mercurio de Santiago. 13 de junio de 1955.

20.- Métodos puestos en práctica para exterminación de perros vagos. El Mercurio de Santiago. 14 de junio de 1955 .

21.- Quinientos perros fueron vacunados en Sector Norte. El Mercurio de Santiago. 18 de junio de 1955.

22.- Berríos E P. Antecedentes en Chile de Enfermedades Virales de los animales domésticos. Enfermedades erradicadas y bajo control. (Fotocopia de comunicación. Sin fecha).

23.- Rabia Humana. MINSAL Chile. Programa de Salud. p 1-19. Abril de 1996.

24.- Favi M V, Ramírez E. Rabia humana en Chile. Laboratorio al día 1996; 12: 7.

25.- Rojas P. Grandes cambios en la Rabia humana en Chile. (Fotocopia de comunicación. Sin fecha ni número de páginas).

26.- Cofré G J. Novedades en vacunas. Rev Chil Pediatr 2003; 74: 366-73.

27.- Favi M. Vigilancia epidemiológica de rabia en especies silvestres en Chile. Bol Soc Infect Vet 2004; 1: 7. 